\title{
Mitotic Activity in Glioblastoma Correlates with Estimated Extravascular Extracellular Space Derived from Dynamic Contrast-Enhanced MR Imaging
}

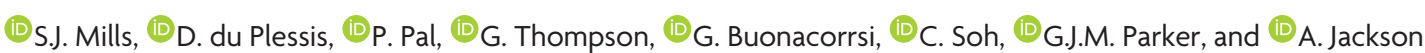

t

\begin{abstract}
BACKGROUND AND PURPOSE: A number of parameters derived from dynamic contrast-enhanced MR imaging and separate histologic features have been identified as potential prognosticators in high-grade glioma. This study evaluated the relationships between dynamic contrast-enhanced MRI-derived parameters and histologic features in glioblastoma multiforme.
\end{abstract}

MATERIALS AND METHODS: Twenty-eight patients with newly presenting glioblastoma multiforme underwent preoperative imaging (conventional imaging and T1 dynamic contrast-enhanced MRI). Parametric maps of the initial area under the contrast agent concentration curve, contrast transfer coefficient, estimate of volume of the extravascular extracellular space, and estimate of blood plasma volume were generated, and the enhancing fraction was calculated. Surgical specimens were used to assess subtype and were graded (World Health Organization classification system) and were assessed for necrosis, cell density, cellular atypia, mitotic activity, and overall vascularity scores. Quantitative assessment of endothelial surface area, vascular surface area, and a vascular profile count were made by using CD34 immunostaining. The relationships between MR imaging parameters and histopathologic features were examined.

RESULTS: High values of contrast transfer coefficient were associated with the presence of frank necrosis $(P=.005)$. High values of the estimate of volume of the extravascular extracellular space were associated with a fibrillary histologic pattern $(P<.01)$ and with increased mitotic activity $(P<.05)$. No relationship was found between mitotic activity and histologic pattern, suggesting that the correlation between the estimate of volume of the extravascular extracellular space and mitotic activity was independent of the histologic pattern.

CONCLUSIONS: A correlation between the estimate of volume of the extravascular extracellular space and mitotic activity is reported. Further work is warranted to establish how dynamic contrast-enhanced MRI parameters relate to more quantitative histologic measurements, including markers of proliferation and measures of vascular endothelial growth factor expression.

ABBREVIATIONS: DCE-MRI = dynamic contrast-enhanced MRI; EnF = enhancing fraction; GBM = glioblastoma multiforme; IAUC 60 initial area under the contrast agent concentration curve; $K^{\text {trans }}=$ contrast transfer coefficient; $v_{e}=$ volume of the extravascular extracellular space per unit tissue volume; $V E G F=$ vascular endothelial growth factor; $v_{p}=$ volume of the blood plasma per unit tissue volume

$\mathbf{G}$ liomas are the most common primary cerebral tumor of adulthood. They are histologically classified according to the World Health Organization criteria into tumor grade and subtype, ${ }^{1}$ which are important for determining appropriate treatment. Within given histologic subtypes and tumor grades, a num-

Received July 6, 2015; accepted after revision October 6

From the Departments of Neuroradiology (S.J.M., G.T., C.S., A.J.) and Neuropathology (D.d.P., P.P.), Salford National Health Service Foundation Trust, Salford, UK; and Imaging Science and Biomedical Engineering (S.J.M., G.T., G.B., G.J.M.P., A.J.), University of Manchester, Manchester, UK.

This work was funded as part of a Cancer Research UK Clinical Research Training Fellowship, reference C21247/A7473.

Please address correspondence to Samantha Mills, MD, Consultant Neuroradiologist, The Walton Centre, Fazakerley, Liverpool, L9 7L); e-mail: Samantha.Mills@ thewaltoncentre.nhs.uk ber of additional descriptive histopathologic features have been identified as prognosticators, including mitotic activity, ${ }^{2-4}$ microvascular density, ${ }^{5,6}$ and certain vascular patterns. ${ }^{7,8}$ Both proliferation markers, Ki-67 $2-4,7,9,10$ and expression of vascular endothelial growth factor (VEGF), ${ }^{3,5,11-14}$ have also shown a relationship to survival.

Dynamic contrast-enhanced MR imaging (DCE-MR imaging) techniques generate a number of parameters that characterize the microvascular environment. The enhancing fraction $(\mathrm{EnF})$ describes the proportion of perfused tumor tissue. CBV and CBF

\footnotetext{
-- Indicates open access to non-subscribers at www.ajnr.org

$\equiv$ Indicates article with supplemental on-line table.

http://dx.doi.org/10.3174/ajnr.A4623
} 
are commonly derived from dynamic susceptibility contrast techniques, while the volume transfer coefficient $\left(K^{\text {trans }}\right)$, fractional volume of the extravascular extracellular space $\left(\mathrm{v}_{\mathrm{e}}\right)$, and fractional blood plasma volume $\left(\mathrm{v}_{\mathrm{p}}\right)$ can be calculated from T1-weighted DCE-MR imaging. ${ }^{15}$ In glioma, $K^{\text {trans }}, \mathrm{v}_{\mathrm{p}}$, EnF, CBV, and CBF have been shown to relate to histologic grade and/or subtype of tumor. ${ }^{16-21}$ In addition, $K^{\text {trans }}$, EnF, and CBV have been identified as potentially grade-independent prognosticators. ${ }^{22-25}$ The number of studies examining the relationship between DCE-MR imaging parameters and more specific histopathologic features in glioma is currently small and this research predominantly focuses on vascular metrics such as blood volume and flow; however, significant correlations have been described between CBV and microvascular density, ${ }^{26-29}$ VEGF expression, ${ }^{27,30}$ cell density, ${ }^{29}$ endothelial proliferation, ${ }^{31}$ and mitotic activity ${ }^{31}$ and between CBF and endothelial hyperplasia. ${ }^{32}$

More recent studies have focused on the potential of $\mathrm{v}_{\mathrm{e}}$ as an imaging biomarker. In glioma, it has shown value in discriminating histologic grades, ${ }^{33,34}$ but compared with other potential candidate biomarkers of the extravascular extracellular space volume (ADC), on a voxel by voxel basis, no correlation was seen between the 2 metrics, suggesting that these parameters provide independent information about extravascular extracellular space characteristics. ${ }^{35}$ Two separate studies of patients with gliomas of various histologic grades have both reported significant correlations between both $K^{\text {trans }}$ and $\mathrm{v}_{\mathrm{e}}$ and vascular and microvascular density, ${ }^{33,34}$ but neither study comments on the relationship with cellular density or mitotic activity. A high-field, 7T MR imaging study of rat xenografts showed an image-matched significant negative correlation between $v_{e}$ and tumor cellularity. ${ }^{36}$

We hypothesized the following: 1) Larger, rapidly growing tumors would show higher mitotic activity and high angiogenic activity reflected by $K^{\text {trans }}$ and EnF; and 2) more proliferative tumors would have a higher cellular density and mitotic activity associated with lower values of $\mathrm{v}_{\mathrm{e}}$.

\section{MATERIALS AND METHODS Patients}

Ethical approval was obtained, and all patients gave informed consent. All tumors were histologically confirmed as glioblastoma multiforme (GBM) according to the World Health Organization criteria. ${ }^{1}$ All imaging was preoperative, and patients received no treatment other than corticosteroids, which were administered for a minimum of 48 hours before imaging to allow stabilization of the effects of steroids on DCE-MR imaging measures. ${ }^{37} \mathrm{~Pa}-$ tients were excluded from the study if they had a history of renal dysfunction or low estimated glomerular filtration rate $(<30 \mathrm{~mL}$ / $\left.\min / 1.73 \mathrm{~m}^{2}\right)$.

\section{MR Imaging Data Acquisition}

Imaging was performed on a 3T Achieva system (Philips Healthcare, Best, the Netherlands) by using a sensitivity encoding head coil. DCE-MR imaging was acquired in a sagittal oblique orientation to allow improved definition of the arterial input function free from flow-related artifacts. Three precontrast T1 fast-field echo (radiofrequency spoiled gradient-echo) series $\left(2^{\circ}, 5^{\circ}, 16^{\circ}\right)$ were acquired for calculation of baseline T1 maps (TR, $3.5 \mathrm{~ms}$; TE, $1.1 \mathrm{~ms}$; section thickness, $4.2 \mathrm{~mm}$; matrix, $128 \times 128$; FOV, $230 \times$ $230 \times 105 \mathrm{~mm}$ ) in the same geometry. A dynamic, contrast-enhanced acquisition series (TR, $3.5 \mathrm{~ms}$; TE, $1.1 \mathrm{~ms}$; flip angle, $16^{\circ}$; section thickness, $4.2 \mathrm{~mm}$; matrix, $128 \times 128$; FOV , $230 \times 230 \times$ $105 \mathrm{~mm}$ ) consisting of 100 volumes with temporal spacing of approximately 3.4 seconds followed. A bolus dose of $0.1 \mathrm{mmol} / \mathrm{kg}$ (body weight) of gadolinium-based contrast agent (gadodiamide; Gd-DTPA-BMA; Omniscan; GE Healthcare, Piscataway, New Jersey) was injected at a rate of $3 \mathrm{~mL} / \mathrm{s}$, after acquisition of the fifth image volume. Pre- and postcontrast T1-weighted imaging sequences (TR, $9.3 \mathrm{~ms}$; TE, $4.6 \mathrm{~ms}$ ) were acquired in the same sagittal oblique geometry for definition of the volume of interest of the whole tumor.

\section{MR Imaging Data Analysis}

An experienced neuroradiologist (S.J.M.) manually defined VOIs for each tumor. The VOI corresponded to the enhancing tumor and all nonenhancing tissue contained within it on the postcontrast T1-weighted images. This technique of VOI definition has previously shown good interobserver agreement (intraclass correlation coefficient $>0.94) .{ }^{38}$ Pharmacokinetic analysis was performed on all pixels within the VOI that showed significant enhancement. Parametric maps of $K^{\text {trans }}, v_{p}, v_{e}$, and initial area under the contrast agent concentration curve $\left(\mathrm{IAUC}_{60}\right)$ were produced by using in-house software (MaDyM; Manchester Dynamic Modeling, Manchester, UK) and the extended Tofts and Kermode pharmacokinetic model. ${ }^{15}$ Automated arterial input functions were generated from an appropriately chosen section, which included the internal carotid artery. ${ }^{39}$ Summary statistics for each parameter were generated for enhancing tumor tissue.

For each tumor, EnF initial area under the contrast agent concentration curve $\left(\mathrm{EnF}_{\mathrm{IAUC60}>0}\right)$ and thresholded EnF $\left(\mathrm{EnF}_{\mathrm{IAUC60}>2.5}\right)$ were calculated by dividing the enhancing volume (volume of voxels with $\mathrm{IAUC}_{60}>0 \mathrm{mmol} / \mathrm{s}$ for $\mathrm{EnF}_{\text {IAUC60 }>0}$ and the volume of voxels with $\mathrm{IAUC}_{60}>2.5 \mathrm{mmol} / \mathrm{s}$ for EnF $_{\text {IAUC60 }>2.5}$ ) by the total volume of the tumor VOI. The cutoff threshold of $\mathrm{IAUC}_{60}>2.5 \mathrm{mmol} / \mathrm{s}$ for $\mathrm{EnF}_{\text {IAUC60 }>2.5}$ was previously identified as an optimal threshold for allowing the distinction of high- from low-grade gliomas. ${ }^{40}$

\section{Histopathologic Data Analysis}

Two experienced neuropathologists (D.d.P. and P.P.) performed the histopathologic analysis. Histologic specimens were assessed for the following: necrosis (presence or absence of frank and/or geographic necrosis), cell density (3-point grading score), cell atypia (3-point grading score), mitotic activity (number of mitotic figures seen per 10 high-power-field units), infiltrates (presence or absence of lymphocytes and/or macrophages), tumor vascular pattern (presence or absence of the following features: endothelial hypertrophy and/or hyperplasia, glomeruloid structures, granulation tissue, large-vessel density, thrombosis, sclerosed vessels), an overall vascular density score (3-point grading score), and histologic pattern (fibrillar, gemistocytic, oligodendrocytes, sarcomatous, giant cells, and small cells) in conjunction with standard histopathologic subtyping and grading according to the World Health Organiza- 

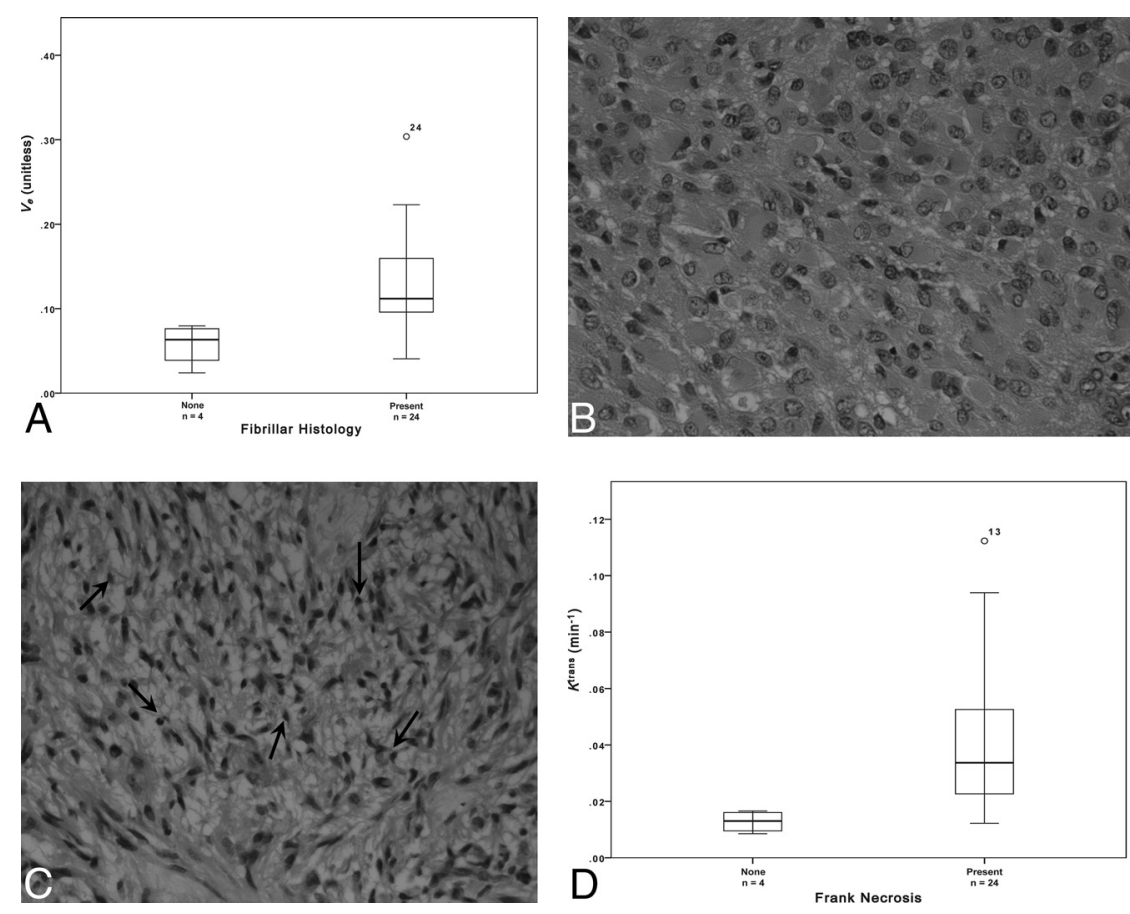

FIG 1. A, Boxplot of fibrillar histology and $v_{\mathrm{e}}$ (estimated $P=.007$ ). Sample histologic specimens showing tumors without $(B)$ and with $(C)$ the presence of fibrils (small fibers measuring approximately $1 \mathrm{~mm}$, black arrows, C). H\&E stain $\times 40$ magnification. $D$, Boxplot of frank necrosis and $K^{\text {trans }}$ (estimated $P=.005$ ).

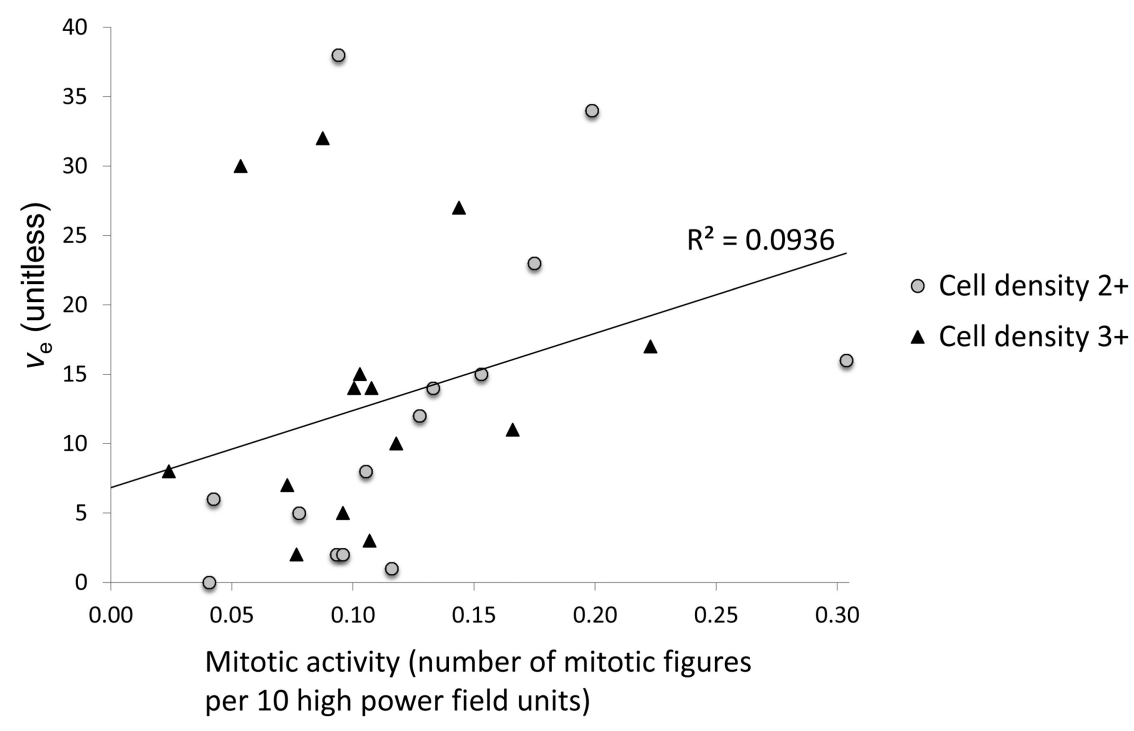

FIG 2. Scatterplot of mitotic activity versus $v_{e}(P=.012, \rho=0.470)$, marker shapes depict separate scores of cell density measures.

tion classification criteria. ${ }^{1}$ Vascular and histologic features were not mutually exclusive; therefore, $>1$ feature could be described in a given tumor specimen.

Quantitative measurement of the endothelial surface area, the vascular surface area, and the vascular profile count per square millimeter was made by using CD34 immunostaining and dedicated image-analysis software.

\section{Statistical Analysis}

Statistical analysis was performed by using SPSS (Version 15.0; IBM, Armonk, New York) nonparametric statistical tests. While histologic parameters produce a binary classification (necrosis, infiltrates, vascular patterns, and histologic patterns), Mann-Whitney $U$ tests were performed to test the hypothesis that MR imaging parameter values did not differ among groups. While histologic features produce categoric scores (cell density, cell atypia, and overall vascular score), multivariate analysis of variance was used to test the hypothesis that MR imaging parameter values did not differ among groups. Spearman correlation analysis was performed to assess the relationship between quantitative histologic measures (mitotic activity, endothelial surface area, vascular surface area, and vascular profile count per square millimeter) and MR imaging parameters and to identify correlations among the individual MR imaging measurements. For Mann-Whitney $U$ and ANOVA testing, a result was considered significantly different with $P<$ .01 , given the number of variables assessed. For the Spearman correlation analysis, significance was $<.05$.

\section{RESULTS}

Twenty-eight untreated newly presented GBMs were included in the study (10 women; age range, 38-76 years; mean, 60 years). Histologic specimens were obtained from 12 biopsies and 16 surgical debulkings. The results of statistical analyses for comparisons of histologic and MR imaging measures are summarized in the On-line Table.

The presence of frank necrosis was associated with significantly higher values of $K^{\text {trans }}(P<.01$, Fig 1$)$. Significantly higher values of $v_{e}$ were seen in the presence of fibrillary histology (estimated $P<.01$, Fig 1). A positive correlation was found between $\mathrm{v}_{\mathrm{e}}$ and mitotic activity $(P<.05, \rho=0.470$, Fig 2$)$. No relationship was seen between mitotic activity and any of the descriptive or semiquantitative histology measures, suggesting that the relationship between $\mathrm{v}_{\mathrm{e}}$ and mitotic activity is independent of the relationship between $\mathrm{v}_{\mathrm{e}}$ and the presence of fibrillar histology. No correlation was observed between $\mathrm{v}_{\mathrm{e}}$ and cell density.

Cross-correlations between individual MR imaging parameters are summarized in Table 1. Positive correlations were found between $K^{\text {trans }}$ and all other MR imaging parameters. Significant correlations were present between $\mathrm{v}_{\mathrm{e}}$ and $K^{\text {trans }}(P<.05$ and $\rho=$ $0.450)$ and between $v_{p}$ and EnF. Mitotic activity did not correlate 
Table 1: Cross-correlations of MRI parameters ${ }^{\mathrm{a}}$

\begin{tabular}{llllc}
\hline & \multicolumn{4}{c}{ Untreated GBM $(\boldsymbol{n}=28)$} \\
\cline { 2 - 5 } & \multicolumn{1}{c}{$\mathrm{v}_{\mathbf{e}}$} & \multicolumn{1}{c}{$\mathrm{v}_{\mathrm{p}}$} & $\mathrm{EnF}_{\text {IAUC60>0 }}$ & EnF $_{\text {IAUC60>2.5 }}$ \\
\hline$K^{\text {trans }}$ & $0.016,{ }^{\mathrm{b}} \rho=0.450$ & $0.006,{ }^{\mathrm{c}} \rho=0.507$ & $0.005^{\mathrm{c}} \rho=0.513$ & $<0.001,{ }^{\mathrm{c}} \rho=0.784$ \\
$\mathrm{v}_{\mathrm{e}}$ & & $0.105, \rho=0.313$ & $0.888, \rho=0.028$ & $0.059, \rho=0.361$ \\
$\mathrm{v}_{\mathrm{p}}$ & & & $0.02,{ }^{\mathrm{b}} \rho=0.437$ & $<0.001,{ }^{\mathrm{c}} \rho=0.620$ \\
$\mathrm{EnF}_{\text {IAUC60 }>0}$ & & & & $<0.001,{ }^{\mathrm{c}} \rho=0.825$ \\
\hline
\end{tabular}

a Significance levels and Spearman $\rho$ are shown.

b Significance was $P<.05$.

' Significance was $P<.01$.

Table 2: Cross-correlations of quantitative histologic measures ${ }^{a}$

\begin{tabular}{cccc}
\hline & \multicolumn{3}{c}{ Untreated GBM $(\boldsymbol{n}=28)$} \\
\cline { 2 - 4 } & ESA Ratio & VSA Ratio & VPC $/ \mathrm{mm}^{2}$ \\
\hline Mitotic & $0.098, \rho=0.325$ & $0.066, \rho=0.358$ & $0.737, \rho=0.068$ \\
activity & & & \\
ESA ratio & $<0.001,{ }^{\mathrm{b}} \rho=0.993$ & $0.04,{ }^{\mathrm{c}} \rho=0.530$ \\
VSA ratio & & $0.04,,^{\mathrm{c}} \rho=0.532$ \\
\hline
\end{tabular}

Note:-VPC indicates vascular profile count per square millimeter; VSA, vascular surface area; ESA, endothelial surface area.

a Significance levels and Spearman $\rho$ are shown.

b Significance was $P<.01$.

c Significance was $P<.05$.

with any quantitative vascular measure, but cross-correlation was seen across all 3 histologic vascular metrics (Table 2). No other significant relationships were identified among histologic measures.

\section{DISCUSSION}

While there has been considerable interest in the development of imaging biomarkers for use in clinical trials, most DCE-MR imaging studies have focused on identifying correlates of vascularity and angiogenesis. ${ }^{41}$ This study identified an unexpected positive correlation between $\mathrm{v}_{\mathrm{e}}$, a parameter thought to reflect extravascular extracellular space volume, and mitotic activity. No relationships were identified among the previously described DCE-MR imaging prognosticators, $K^{\text {trans }}$ and $\mathrm{v}_{\mathrm{p}}$, and mitotic activity or between vascular patterns and DCE-MR imaging measures.

The parameter $\mathrm{v}_{\mathrm{e}}$ is often overlooked in DCE-MR imaging studies. In cerebral tumors, it has the potential to distinguish intra- from extra-axial tumors ${ }^{42,43}$ and exhibits increased values with increasing tumor grade. ${ }^{33,34,42,44}$ It has also demonstrated sensitivity in identifying changes in response to treatment with corticosteroids, with decreases in $v_{\mathrm{e}}$ presumably reflecting a reduction in interstitial edema. ${ }^{45,46}$ In a study of vestibular schwannomas, meningiomas, and gliomas, no direct measure of the extravascular extracellular space or cell density measure was made, but $\mathrm{v}_{\mathrm{e}}$ values in schwannoma were significantly larger than those in glioma, where cell density is higher. ${ }^{43}$ In a study comparing $\mathrm{v}_{\mathrm{e}}$ with ADC in glioma, no relationship was found between the 2 metrics, suggesting that these parameters may provide independent information about the extravascular extracellular space. ${ }^{35}$ This may reflect the existence of separate extravascular leakage compartments characterized by fast and slow contrast exchange rates, possibly reflecting the presence of slow leakage/diffusion into and out of necrotic tumor spaces. ${ }^{42,47,48}$ Previous studies have also reported correlations between microvascular density and both $\mathrm{v}_{\mathrm{e}}$ and $K^{\text {trans }} \cdot{ }^{33,34}$ We did not find this correlation in our study, but there was a cross-correlation between the DCE-MR imaging parameters $\mathrm{v}_{\mathrm{e}}$ and $K^{\text {trans }}$, raising the possibility that the correlation reported in the previous studies reflects the relationship of $\mathrm{v}_{\mathrm{e}}$ with $K^{\text {trans }}$ rather than microvascular density. A previous rat xenograft study has reported a correlation between $\mathrm{v}_{\mathrm{e}}$ and cellular density, ${ }^{36}$ but our current study found no such relationship.

Histologic measures of cell density are often a count of the number of cell nuclei per unit area and without quantification of the amount of tissue the cells occupy; thus, an increase in histologic cell density may reflect an increase in the number of cells, but not necessarily a decrease in extravascular extracellular space if the cells are small. There are potential modeling problems associated with the calculation of $\mathrm{v}_{\mathrm{e}}$. Clearly it can be estimated only in perfused tissue where there is significant leakage of contrast agent. ${ }^{35}$ This problem means that summary statistics presented in this and other studies reflect only perfused tissue with contrast agent leakage, in contrast to diffusionweighted imaging, in which high ADC values are seen in association with necrosis. We have specifically excluded nonperfusing tissue from estimates of summary statistics, which could otherwise produce artificially low values of $\mathrm{v}_{\mathrm{e}}$. In addition, the relatively low dynamic sampling duration (6 minutes) will affect $\mathrm{v}_{\mathrm{e}}$ estimates to some degree. First, model fitting errors (assuming that the model is correct) will result from undersampling, but modeling studies suggest that these fitting errors are likely to be very small. ${ }^{49}$ Second, short sampling times will lead to relative underrepresentation of slow tissue exchange compartments, which would tend to reduce the impact of necrotic tissue on $v_{e}$ estimations as described in several studies. ${ }^{42,47,48}$ These potential model fitting errors and short sampling times imply that tumors with greater necrosis would have shown higher $\mathrm{v}_{\mathrm{e}}$ values if sampling had continued for a longer time and that the measured values of $v_{e}$ in this study are more likely to reflect the extravascular extracellular space fraction in viable tissue.

The positive correlation between $\mathrm{v}_{\mathrm{e}}$ and mitotic activity is surprising. Tumors with larger $\mathrm{v}_{\mathrm{e}}$ values exhibited more mitotic activity, the inverse of what one might expect (and the inverse of our initial hypothesis), whereby more proliferative tumors would be more densely packed with cells. Neither mitotic activity nor $\mathrm{v}_{\mathrm{e}}$ related to the presence of necrosis, though the lack of a relationship between $\mathrm{v}_{\mathrm{e}}$ and necrosis may, in part, reflect the relatively low dynamic collection period (see above). These observations suggest that the size of the extravascular extracellular space in perfused enhancing tumor tissue is truly related to mitotic rate and not simply a reflection of elevated measures of $\mathrm{v}_{\mathrm{e}}$ due to increased necrosis in rapidly proliferating tumors.

This suggestion is initially counterintuitive. In normally developing tissues, mitotic activity is higher in areas of low cell packing due to the inhibition of proliferation in response to cell-to-cell contact, a process known as contact inhibition of proliferation in developing normal tissue. ${ }^{50}$ No similar relationship has been described in malignant tissues, and loss of contact inhibition of mitosis is one of the hallmarks of the cancer cell. ${ }^{51}$ This finding leads to the hypothesis, stated in the introduction, that rapidly prolif- 
erating tumors will continue to proliferate, leading to increased cell density and a decreased size of the extravascular extracellular space and consequently of $\mathrm{v}_{\mathrm{e}}$. We have no evidence to explain why the observed relationship should exist. One possible explanation may be that tumors with high cellular density still have impaired responses to tumoral growth factors despite loss of contact inhibition of proliferation. ${ }^{52}$ Another possible explanation is that tumors with short mitotic cycles are characterized by a reduced time for cellular maturation, resulting in smaller cells and reduced cell packing. Whatever the underlying biologic mechanism, this finding appears particularly interesting and requires further study.

The ability to obtain an MR imaging-based biomarker of mitotic activity and/or tumor cell proliferation is highly desirable. The findings presented here may be tumor-specific or reflect an unrecognized phenotype, but the possibility that $\mathrm{v}_{\mathrm{e}}$ may be a potential marker of mitotic activity merits further evaluation.

The data also demonstrated a positive relationship between the presence of tumor cell fibrils within the histologic specimens and higher $\mathrm{v}_{\mathrm{e}}$, though the numbers were very small $(n=4)$. Fibrillar cell processes are cell extensions containing cytoplasm, which are surrounded by cell membranes. These are visible through a microscope and allow tumor astrocytes to be recognized as "fibrillar." A less cell-dense arrangement due to such cell extensions and/or intercellular edema facilitate its recognition via light microscopy. Thus, the ability to identify fibrillar cell processes suggests that the tumor cells are more loosely packed or that there is localized extracellular edema. No relationship was identified between fibrillar histology and mitotic activity, indicating that the relationships between $\mathrm{v}_{\mathrm{e}}$ and these measures are independent.

Most previous work evaluating the relationship between specific histologic features and DCE-MR imaging has focused predominantly on CBV derived from DSC techniques with significant relationships seen among $\mathrm{CBV}$ and microvascular density, ${ }^{26-29}$ VEGF expression, ${ }^{27,30}$ cell density, ${ }^{29}$ endothelial proliferation, ${ }^{31}$ and mitotic activity. ${ }^{31}$ No such relationships were identified between these latter 3 measures and $v_{p}$ in this study. A study by Lüdemann et $\mathrm{al}^{53}$ compared a variety of MR imaging techniques with $\mathrm{H}_{2}\left[{ }^{15} 0\right]$-PET for measuring perfusion and found that while both DSC and T1-weighted DCE-MR imaging techniques correlated with the criterion standard $\mathrm{H}_{2}\left[{ }^{15} 0\right]$-PET measure, only borderline correlation was seen between the DSC techniques and the T1-weighted technique, whereby DSC-derived blood volumes were generally lower than those derived from the T1-weighted DCE-MR imaging technique. This finding may account for the failure of $v_{p}$ to relate to any of the histologic measures in this study.

The major limitation of the present work is the lack of stereotactic image-matched histologic specimens; therefore, correlation between the histology and the DCE-MR imaging measurements at a local level cannot be made. GBMs are notoriously heterogeneous tumors, and histologic analysis of small tumor specimens may lead to undergrading of a tumor if the sample is not a true reflection of the tumor as a whole. At the time of the study, image-matched histologic samples were not obtained and there was no concurrent postoperative imaging performed, which could have helped to identify the site of the histologic sample. All histologic specimens in this study did confirm the diagnosis of
GBM and therefore are considered representative samples. Previous nonimage-registered studies comparing $\mathrm{v}_{\mathrm{e}}$ with histopathologic vascular measures have been reported, but these have been performed with a selection of 3-4 small ROIs, taking the maximal value of $\mathrm{v}_{\mathrm{e}}$ and $K^{\text {trans }}, 3,34$ which is unlikely to provide a representation of the tumor as a whole. In our current study, for the DCE-MR imaging measures $K^{\text {trans }}, v_{\mathrm{e}}$, and $\mathrm{v}_{\mathrm{p}}$, median values from whole-tumor VOIs were used. Studies using whole-tumor VOIs have previously identified significant differences in DCE-MR imaging parameters among tumor grades ${ }^{17}$ and have been shown to convey important potential prognostic information. ${ }^{25}$ Thus, a comparison between small histologic samples and DCE-MR imaging parameters from whole-tumor VOIs seems reasonable. Further work is required to confirm that the correlations identified in the current study hold true for image-matched stereotactic samples. In addition, some histologic features such as Ki-67 and VEGF expression, which have previously shown correlation with DSC-MR imaging-derived CBV, ${ }^{20,26-30}$ were not available.

\section{CONCLUSIONS}

The DCE-MR imaging-derived measure $\mathrm{v}_{\mathrm{e}}$ has been identified as a potential correlate of mitotic activity in GBM. While this is an interesting result, our understanding of the biologic mechanisms responsible for this possible relationship is limited. Further work with the correlation of $\mathrm{v}_{\mathrm{e}}$ to more precise measures of cell density, additional markers of cellular and vascular proliferation, and measures of VEGF expression is warranted.

Disclosures: Samantha J. Mills_RELATED: Grant: C21247/A7473 Cancer Research UK/ RCR clinical training fellowship, September 2006 to March 2010.* Giovanni Buonacorrsi-RELATED: Grant: Cancer Research UK, Comments: salary paid by Cancer Research UK Programme grant via the University of Manchester; UNRELATED: Employment: Bioxydyn commenced since the completion of this work. Geoffrey J.M. Parker-UNRELATED: Board Membership: Bioxydyn, Comments: founder and CEO of Bioxydyn, a company with an interest in imaging biomarkers, including DCE-MRI, and their application to cancer and other conditions; Consultancy: GlaxoSmithKline, Comments: consultancy on advanced imaging methods for clinical trials; Employment: Bioxydyn, Comments: part-time employment as CEO of Bioxydyn, a company with an interest in imaging biomarkers, including DCE-MRI, and their application to cancer and other conditions; Grants/Grants Pending: Cancer Research UK, * Engineering and Physical Sciences Research Council, ${ }^{\star}$ Comments: Programme Grant and project grants to develop DCE-MRI and other MRI methods for use in cancer and neurologic conditions; Royalties: for DCE-MRI software, licensed via the University of Manchester; royalties shared between staff and the University; Stock/Stock Options: Bioxydyn, Comments: Bioxydyn is a company with an interest in imaging biomarkers, including DCE-MRI, and their application to cancer and other conditions. Alan Jackson-RELATED: Grant: Cancer Research UK.* *Money paid to the institution.

\section{REFERENCES}

1. Louis DN, Ohgaki H, Wiestler OD, et al. The 2007 WHO Classification of Tumours of the Central Nervous System. Acta Neuropathol 2007;114:97-109 Medline

2. Struikmans H, Rutgers DH, Jansen GH, et al. Prognostic relevance of MIB-1 immunoreactivity, S-phase fraction, 5-bromo-2' -deoxyuridine labeling indices, and mitotic figures in gliomas. Radiat Oncol Investig 1999;7:243-48 Medline

3. Korshunov A, Golanov A, Sycheva R. Immunohistochemical markers for prognosis of anaplastic astrocytomas. J Neurooncol 2002;58: 203-15 CrossRef Medline

4. Scott JN, Rewcastle NB, Brasher PM, et al. Which glioblastoma multiforme patient will become a long-term survivor? A populationbased study. Ann Neurol 1999;46:183-88 Medline

5. Abdulrauf SI, Edvardsen K, Ho KL, et al. Vascular endothelial AJNR Am J Neuroradiol 37:811-17 May 2016 www.ajnr.org 815 
growth factor expression and vascular density as prognostic markers of survival in patients with low-grade astrocytoma. J Neurosurg 1998;88:513-20 CrossRef Medline

6. Yao Y, Kubota T, Takeuchi H, et al. Prognostic significance of microvessel density determined by an anti-CD105/endoglin monoclonal antibody in astrocytic tumors: comparison with an anti-CD31 monoclonal antibody. Neuropathology 2005;25:201-06 CrossRef Medline

7. Preusser M, Gelpi E, Matej R, et al. No prognostic impact of survivin expression in glioblastoma. Acta Neuropathol 2005;109:534-38 CrossRef Medline

8. Birner P, Piribauer M, Fischer I, et al. Vascular patterns in glioblastoma influence clinical outcome and associate with variable expression of angiogenic proteins: evidence for distinct angiogenic subtypes. Brain Pathol 2003;13:133-43 Medline

9. Colman H, Giannini C, Huang L, et al. Assessment and prognostic significance of mitotic index using the mitosis marker phosphohistone $\mathrm{H} 3$ in low and intermediate-grade infiltrating astrocytomas. Am J Surg Pathol 2006;30:657-64 Medline

10. Coleman KE, Brat DJ, Cotsonis GA, et al. Proliferation (MIB-1 expression) in oligodendrogliomas: assessment of quantitative methods and prognostic significance. Appl Immunohistochem Mol Morphol 2006;14:109-14 CrossRef Medline

11. Flynn JR, Wang L, Gillespie DL, et al. Hypoxia-regulated protein expression, patient characteristics, and preoperative imaging as predictors of survival in adults with glioblastoma multiforme. Cancer 2008;113:1032-42 CrossRef Medline

12. Karayan-Tapon L, Wager M, Guilhot J, et al. Semaphorin, neuropilin and VEGF expression in glial tumours: SEMA3G, a prognostic marker? Br J Cancer 2008;99:1153-60 CrossRef Medline

13. Nam DH, Park K, Suh YL, et al. Expression of VEGF and brain specific angiogenesis inhibitor-1 in glioblastoma: prognostic significance. Oncol Rep 2004;11:863-69 Medline

14. Oehring RD, Miletic M, Valter MM, et al. Vascular endothelial growth factor (VEGF) in astrocytic gliomas-a prognostic factor? J Neurooncol 1999;45:117-25 CrossRef Medline

15. Tofts PS. Modeling tracer kinetics in dynamic Gd-DTPA MR imaging. J Magn Reson Imaging 1997;7:91-101 CrossRef Medline

16. Law M, Yang S, Wang H, et al. Glioma grading: sensitivity, specificity, and predictive values of perfusion MR imaging and proton MR spectroscopic imaging compared with conventional MR imaging. AJNR Am J Neuroradiol 2003;24:1989-98 Medline

17. Patankar TF, Haroon HA, Mills SJ, et al. Is volume transfer coefficient (K(trans)) related to histologic grade in human gliomas? AJNR Am J Neuroradiol 2005;26:2455-65 Medline

18. Sugahara T, Korogi Y, Kochi M, et al. Correlation of MR imagingdetermined cerebral blood volume maps with histologic and angiographic determination of vascularity of gliomas. AJR Am J Roentgenol 1998;171:1479-86 CrossRef Medline

19. Roberts HC, Roberts TP, Brasch RC, et al. Quantitative measurement of microvascular permeability in human brain tumors achieved using dynamic contrast-enhanced MR imaging: correlation with histologic grade. AJNR Am J Neuroradiol 2000;21:891-99 Medline

20. Roberts HC, Roberts TP, Bollen AW, et al. Correlation of microvascular permeability derived from dynamic contrast-enhanced MR imaging with histologic grade and tumor labeling index: a study in human brain tumors. Acad Radiol 2001;8:384-91 CrossRef Medline

21. Law M, Young R, Babb J, et al. Comparing perfusion metrics obtained from a single compartment versus pharmacokinetic modeling methods using dynamic susceptibility contrast-enhanced perfusion MR imaging with glioma grade. AJNR Am J Neuroradiol 2006; 27:1975-82 Medline

22. Lev MH, Ozsunar $\mathrm{Y}$, Henson JW, et al. Glial tumor grading and outcome prediction using dynamic spin-echo MR susceptibility mapping compared with conventional contrast-enhanced MR: confounding effect of elevated rCBV of oligodendrogliomas [corrected]. AJNR Am J Neuroradiol 2004;25:214-21 Medline
23. Law M, Young RJ, Babb JS, et al. Gliomas: predicting time to progression or survival with cerebral blood volume measurements at dynamic susceptibility-weighted contrast-enhanced perfusion MR imaging. Radiology 2008;247:490-98 CrossRef Medline

24. Cao Y, Tsien CI, Nagesh V, et al. Survival prediction in high-grade gliomas by MRI perfusion before and during early stage of RT [corrected]. Int J Radiat Oncol Biol Phys 2006;64:876-85 CrossRef Medline

25. Mills SJ, Patankar TA, Haroon HA, et al. Do cerebral blood volume and contrast transfer coefficient predict prognosis in human glioma? AJNR Am J Neuroradiol 2006;27:853-58 Medline

26. Cha S, Johnson G, Wadghiri YZ, et al. Dynamic, contrast-enhanced perfusion MRI in mouse gliomas: correlation with histopathology. Magn Reson Med 2003;49:848-55 CrossRef Medline

27. Haris M, Husain N, Singh A, et al. Dynamic contrast-enhanced derived cerebral blood volume correlates better with leak correction than with no correction for vascular endothelial growth factor, microvascular density, and grading of astrocytoma. J Comput Assist Tomogr 2008;32:955-65 CrossRef Medline

28. Liao W, Liu Y, Wang X, et al. Differentiation of primary central nervous system lymphoma and high-grade glioma with dynamic susceptibility contrast-enhanced perfusion magnetic resonance imaging. Acta Radiol 2009;50:217-25 CrossRef Medline

29. Sadeghi N, D'Haene N, Decaestecker C, et al. Apparent diffusion coefficient and cerebral blood volume in brain gliomas: relation to tumor cell density and tumor microvessel density based on stereotactic biopsies. AJNR Am J Neuroradiol 2008;29:476-82 CrossRef Medline

30. Maia AC Jr, Malheiros SM, da Rocha AJ, et al. MR cerebral blood volume maps correlated with vascular endothelial growth factor expression and tumor grade in nonenhancing gliomas. AJNR Am J Neuroradiol 2005;26:777-83 Medline

31. Sadeghi N, Salmon I, Decaestecker C, et al. Stereotactic comparison among cerebral blood volume, methionine uptake, and histopathology in brain glioma. AJNR Am J Neuroradiol 2007;28:455-61 Medline

32. Callot V, Galanaud D, Figarella-Branger D, et al. Correlations between MR and endothelial hyperplasia in low-grade gliomas. $J$ Magn Reson Imaging 2007;26:52-60 CrossRef Medline

33. Jia ZZ, Gu HM, Zhou XJ, et al. The assessment of immature microvascular density in brain gliomas with dynamic contrast-enhanced magnetic resonance imaging. Eur J Radiol 2015;84: 1805-09 CrossRef Medline

34. Li X, Zhu Y, Kang H, et al. Glioma grading by microvascular permeability parameters derived from dynamic contrast-enhanced MRI and intratumoral susceptibility signal on susceptibility weighted imaging. Cancer Imaging 2015;15:4 CrossRef Medline

35. Mills SJ, Soh C, Rose CJ, et al. Candidate biomarkers of extravascular extracellular space: a direct comparison of apparent diffusion coefficient and dynamic contrast-enhanced MR imaging-derived measurement of the volume of the extravascular extracellular space in glioblastoma multiforme. AJNR Am J Neuroradiol 2010;31: 549-53 CrossRef Medline

36. Aryal MP, Nagaraja TN, Keenan KA, et al. Dynamic contrast enhanced MRI parameters and tumor cellularity in a rat model of cerebral glioma at 7 T. Magn Reson Med 2014;71:2206-14 CrossRef Medline

37. Bastin ME, Carpenter TK, Armitage PA, et al. Effects of dexamethasone on cerebral perfusion and water diffusion in patients with high-grade glioma. AJNR Am J Neuroradiol 2006;27:402-08 Medline

38. Thompson G, Cain J, Jackson A, et al. Interobserver agreement for cerebral glioma volumetrics on conventional MR imaging. In: Proceedings of the 16th Scientific Meeting and Exhibition of the International Society for Magnetic Resonance in Medicine, Toronto, Ontario, Canada. May 3-9, 2008

39. Parker GJ, Jackson A, Waterton JC. Automated arterial input function extraction for T1-weighted DCE-MRI. In: Proceedings of the 11th Scientific Meeting and Exhibition of the International Society for 
Magnetic Resonance in Medicine, Toronto, Ontario, Canada. July 1016,2003

40. Mills SJ, Soh C, O'Connor JP, et al. Tumour enhancing fraction (EnF) in glioma: relationship to tumour grade. Eur Radiol 2009;19: 1489-98 CrossRef Medline

41. O'Connor JP, Jackson A, Parker GJM, et al. DCE-MRI biomarkers in the clinical evaluation of antiangiogenic and vascular disrupting agents. Br J Cancer 2007;96:189-95 CrossRef Medline

42. Lüdemann L, Grieger W, Wurm R, et al. Quantitative measurement of leakage volume and permeability in gliomas, meningiomas and brain metastases with dynamic contrast-enhanced MRI. Magn Reson Imaging 2005;23:833-41 CrossRef Medline

43. Zhu XP, Li KL, Kamaly-Asl ID, et al. Quantification of endothelial permeability, leakage space, and blood volume in brain tumors using combined $\mathrm{T} 1$ and $\mathrm{T} 2{ }^{\star}$ contrast-enhanced dynamic MR imaging. J Magn Reson Imaging 2000;11:575-85 Medline

44. Lüdemann L, Grieger W, Wurm R, et al. Comparison of dynamic contrast-enhanced MRI with WHO tumor grading for gliomas. Eur Radiol 2001;11:1231-41 CrossRef Medline

45. Andersen C, Jensen FT. Differences in blood-tumour-barrier leakage of human intracranial tumours: quantitative monitoring of vasogenic oedema and its response to glucocorticoid treatment. Acta Neurochir (Wien) 1998;140:919-24 CrossRef Medline

46. Armitage PA, Schwindack C, Bastin ME, et al. Quantitative assessment of intracranial tumor response to dexamethasone using dif- fusion, perfusion and permeability magnetic resonance imaging. Magn Reson Imaging 2007;25:303-10 CrossRef Medline

47. Fluckiger JU, Loveless ME, Barnes SL, et al. A diffusion-compensated model for the analysis of DCE-MRI data: theory, simulations and experimental results. Phys Med Biol 2013;58:1983-98 CrossRef Medline

48. Lüdemann L, Hamm B, Zimmer C. Pharmacokinetic analysis of glioma compartments with dynamic Gd-DTPA-enhanced magnetic resonance imaging. Magn Reson Imaging 2000;18:1201-14 CrossRef Medline

49. Cheng HL. Investigation and optimization of parameter accuracy in dynamic contrast-enhanced MRI. J Magn Reson Imaging 2008;28: 736-43 CrossRef Medline

50. McClatchey AI, Yap AS. Contact inhibition (of proliferation) redux. Curr Opin Cell Biol 2012;24:685-94 CrossRef Medline

51. Tumanishvili GD, Salamatina NV. Action of nuclear and cytoplasmic fractions of liver homogenate on liver growth in the chick embryo. J Embryol Exp Morphol 1968;20:53-71 Medline

52. Mayor R, Carmona-Fontaine C. Keeping in touch with contact inhibition of locomotion. Trends Cell Biol 2010;20:319-28 CrossRef Medline

53. Lüdemann L, Warmuth C, Plotkin M, et al. Brain tumor perfusion: comparison of dynamic contrast enhanced magnetic resonance imaging using $\mathrm{T} 1, \mathrm{~T} 2$, and $\mathrm{T} 2^{*}$ contrast, pulsed arterial spin labeling, and H2(15)O positron emission tomography. Eur J Radiol 2009;70: 465-74 CrossRef Medline 